\title{
ANÁLISE DE CRITÉRIOS EM EMPREENDIMENTOS CERTIFICADOS PELO SELO CASA AZUL
}

\author{
OLIVEIRA, Alexandre Sousa Neves de \\ Universidade Federal de Viçosa - MG, e-mail: alexaxandre_sneves@hotmail.com \\ TIBÚRCIO, Túlio Márcio de Salles \\ Universidade Federal de Viçosa - MG, e-mail: tmst83@hotmail.com
}

\begin{abstract}
RESUMO
A construção civil é considerada uma grande atividade geradora de resíduos e causadora de grandes impactos ao meio ambiente. Diante deste cenário, percebe-se a necessidade de redução dos danos causados por este e surgem diversos métodos avaliativos de impactos ambientais importantes como o Selo Casa Azul, da Caixa Econômica Federal (CEF). Este artigo, produto de uma disciplina de pós-graduação, tem como objetivo promover uma análise comparativa dos resultados dos critérios livres atendidos por empreendimentos certificados pela CEF. Esta pesquisa tem abordagem qualitativa, natureza aplicada e objetivos exploratórios, que se sustentam em uma revisão de literatura e análise documental para coleta de dados e estabelecimento dos critérios de análise conforme o Selo Casa Azul da CEF. Como resultado, foi apontado o atendimento ou não dos critérios estabelecidos pela CEF obtidas pelos empreendimentos, bem como uma análise e justificativa do cumprimento dos critérios em questão.
\end{abstract}

Palavras-chave: Construção Civil, Sustentabilidade, Certificação Ambiental, Selo Casa Azul, Avaliação Ambiental.

\begin{abstract}
Civil Construction is considered a major waste generator and causes great impacts to the environment. Within this scenario, it is perceived the need to reduce the damages caused by this, and several evaluation methods emerge from important environmental impacts such as the Seal Casa Azul, from Caixa Econômica Federal (CEF). This article, product of a graduate course, aimed to promote a comparative analysis of the results of the free criteria served by enterprises certified by CEF. It is a qualitative research, based on a literature review and documentary analysis for data collection and establishment of the analysis criteria according to CEF's Casa Azul Seal. Results pointed out whether or not the criteria established by CEF obtained by the enterprises were met, as well as an analysis and justification of compliance with the criteria in question.
\end{abstract}

Keywords: Construction Industry, Sustainability, Environment Certification, Casa Azul Seal, Environment Assessment.

\section{INTRODUÇÃO}

A construção civil é vista como uma grande geradora de resíduos. Em sua produção, também causa grandes impactos ao meio ambiente, principalmente, com o considerável consumo de recursos naturais não renováveis. Neste sentido, esta vem sendo o centro de discussões de assuntos

OLIVEIRA, A. S. N.; TIBÚRCIO, T. M. S. Análise de critérios em empreendimentos certificados pelo selo Casa Azul. In: SIMPÓSIO BRASILEIRO DE QUALIDADE DO PROJETO NO AMBIENTE CONSTRUÍDO, 6., 2019, Uberlândia. Anais... Uberlândia: PPGAU/FAUeD/UFU, 2019. p. 930-942. DOI https://doi.org/10.14393/sbqp19086. 
relacionados com a sustentabilidade (ZANDEMONIGNE; TIBÚRCIO, 2013); sendo, em especial, a construção de edifícios, considerada a atividade humana que provoca maiores impactos sobre o meio ambiente (SILVA, 2003).

Silva (2003, p.33) ainda destaca que a necessidade da criação de meios para avaliar as edificações, partiu da crítica; "mesmo os países que acreditavam dominar os conceitos de projeto ecológico, não possuíam meios para verificar quão verdes eram de fato os seus edifícios". Grunberg et al. (2014) reforçam ao afirmarem que não há como existir a verificação do atendimento às questões de sustentabilidade sem haver a imposição do cumprimento de critérios. Diante isto, vários sistemas para avaliação ambiental de edifícios, vem sendo criados em vários países.

Dada a importância das construções sustentáveis, a Caixa Econômica Federal (CEF) desenvolveu o Selo Casa Azul, com a finalidade de reconhecer empreendimentos que implantam medidas de redução aos impactos ambientais através da certificação ambiental. Características estas são avaliadas devido a critérios relacionados com as seis categorias do selo: qualidade urbana (1), projeto e conforto (2), eficiência energética (3), conservação dos recursos materiais (4), gestão de água (5) e práticas sociais (6), onde cada uma desta propõem métodos para cumprirem aos critérios presentes nestas seis categorias (CEF, 2010).

O método de avaliação do Selo Casa Azul é baseado em 53 critérios, sendo 19 obrigatórios e 34 facultativos, além disso, o selo possui três graduações, bronze, prata e ouro. O primeiro (bronze) é somente concedido a empreendimentos cujo valor de avaliação da unidade habitacional não ultrapassem os limites pré-determinados de acordo com sua localidade. Para alcançar o selo bronze é necessário atender a 19 critérios obrigatórios, já a gradação prata, é necessário atender além dos 19 critérios obrigatórios, mais 6 de livre escolha e, por fim, para alcançar o selo ouro é preciso atender aos 19 critérios obrigatórios e a mais 12 de livre escolha (CEF, 2010).

Além disto, os itens obrigatórios em alguns casos podem ser substituídos pelos de livre escolha, como o caso do empreendimento Bela Cintra, que na categoria 5 (Gestão da Água) de acordo com o quadro-resumo de categorias, critérios e classificação do empreendimento', o empreendimento fez uma substituição do atendimento do critério obrigatório de número "5.8" que corresponde ao critério de "Áreas Permeáveis", com o critério "5.6", correspondente ao critério de "Retenção de Águas Pluviais".

O Selo Casa Azul, desde sua criação em 2010, certificou apenas vinte e seis empreendimentos de acordo com Tomás e Lins (2019). Campos e Ferrão (2018) criticam a este fato considerando que, a Caixa Econômica Federal sendo a maior financiadora habitacional do Brasil e também uma empresa certificadora, desde a criação do Selo Casa Azul em 2010 contam com o menor número de habitações certificadas.

Com isto, os resultados apresentados e caracterizados tecnicamente nesta pesquisa, espera-se facilitar a futuros empreendimentos e empreendedores na

\footnotetext{
1 Quadro-resumo de categorias, critérios e classificação do empreendimento BC Bela Cintra. Disponível em:

<http://www.caixa.gov.br/Downloads/selo_casa_azul/Ficha_Selo_Bela_Cintra.pdf>. Acesso em: 04 jun. 2019.
} 
escolha do atendimento a critérios de livre escolha, nos quais hão atualmente a não identificação no atendimento, podendo optarem também, na ponderação da escolha do cumprimento entre critérios mais acessíveis sendo considerados os de maiores índices de cumprimento, como também identificarem os critérios revelados como sendo os menos atendidos expressando-se dificuldades ao seu atendimento. Pretende-se desta forma, direcionar a pesquisa para novas propostas estrategicamente gerenciadas para serem incorporadas a futuros empreendimentos de empresas com esta visão.

\section{FUNDAMENTAÇÃO}

Frente a toda problemática de renovação de recursos, a questão da sustentabilidade é premente na área da arquitetura e construção civil, tornando as práticas voltadas a sustentabilidade como possibilidades concretas para se tornar possível a interação do homem com o ambiente, e, neste contexto, as certificações ambientais vêm desempenhando o seu papel de forma satisfatória.

Certificações estas que foram criadas em meio as necessárias adequações do setor da construção civil diante das degradações ambientais em todo o mundo, no intuito de comprovar a legitimidade quanto à estas conformações sustentáveis. São constituídas por diversos métodos avaliativos dos impactos ambientais, que promovem e determinam parâmetros e metas. Silva (2003, p.33) ainda destaca que a necessidade da criação de meios para avaliar as edificações, partiu da crítica "mesmo os países que acreditavam dominar os conceitos de projeto ecológico, não possuíam meios para verificar quão verdes eram de fato os seus edifícios".

Desta forma, Grunberg et al. (2014) reforçam em afirmar que não há como haver esta verificação no atendimento às questões de sustentabilidade sem haver a imposição do cumprimento de critérios. Diante isto, foram desenvolvidos diversos sistemas para avaliação ambiental de edifícios, em vários países.

Nesse viés, o Brasil desenvolveu normas, certificações e selos ambientais que consideram os requisitos internacionais, contudo, adaptadas para a realidade do país em muitos casos. Dentre as certificações ambientais mais utilizadas no Brasil, segundo Campos e Ferrão (2018), estão: Selo Procel Edifica, Selo Casa Azul Caixa, a iniciativa da PMRJ com o Selo Qualiverde, e quatro internacionais: HQE, França, o LEED, Estados Unidos, BREEAM, Grã-Bretanha, e DNGB, Alemanha, sendo estes dois últimos em fase de implantação no mercado brasileiro.

Grünberg, Medeiros e Tavares (2014), ao utilizar o método de Análise Hierárquica (Analytic Hierarchic Process, AHP) para comparar os sistemas de certificação ambiental que consideram mais relevantes e adequados para com a realidade brasileira, compararam os selos, LEED for Homes, AQUA e Selo Casa Azul. Nos resultados obtidos, por este estudo, chegaram à conclusão que entre estes, o selo LEED for homes, não se adequa bem as condições brasileiras, além de que, sua aplicação no Brasil, está sendo feita apenas em empreendimentos comerciais como também, destacou o Selo Casa Azul considerando ser o agente de certificação que melhor condiz com a realidade brasileira conforme foi criado. O selo AQUA, sendo este uma 
adaptação do selo Francês, ficou logo em seguida com diferença irrelevante, demonstrando a adaptação do selo para com a realidade brasileira adequada.

Dinamarco (2016) corrobora destacando que o Selo Casa Azul, foi o primeiro sistema de classificação da sustentabilidade de projetos elaborado para a realidade da construção habitacional brasileira, concretizando-se como uma importante ferramenta certificadora socioambiental, para os empreendimentos financiados pela CEF.

Rocha e Falcão (2017) acedem ao fato destas três certificações serem as mais relevantes na atuação no Brasil. Realizaram uma pesquisa que difere a de Grünberg, Medeiros e Tavares (2014), onde propõem a comparação no método derivada da analogia entre estas, abordando o critério de semelhanças, diferenças e exigências para seu atendimento. Em seus resultados, apresentam o Selo Casa Azul, como o mais simples em termos de requisitos e exigências a serem adotadas para a certificação, recomendam como opção para empresas que almejam iniciar a construção de edifícios com certificação ambiental. Consideram como um processo de iniciação a certificação o Selo Casa Azul, onde seria o ponto de partida para prosseguir até certificações mais exigentes e detalhadas como o selo LEED oU AQUA, apontando um passo evolutivo.

Rocha e Falcão (2017) criticam o fato que, desde a criação do Selo Casa Azul em 2010, a Caixa Econômica Federal sendo a maior financiadora habitacional do Brasil e também uma empresa certificadora, tenha apenas 19 habitações certificadas até o ano de 2015.

Mesmo que Tomás e Lins (2019) confirmem que atualmente são 26 edificações certificadas desde a criação do Selo, com a inclusão da Vila dos Atletas em 2016 com os Condomínios 1 ao 5, 7, e 9, o número de habitações certificadas com o Selo da Caixa Econômica Federal, é um número considerado baixo, pois, desde que o Banco Nacional de Habitação (BNH) foi incorporado pela CEF em 1986, a Caixa Econômica Federal é conhecida como o "banco do financiamento habitacional" e como "o agente público responsável por cerca de 70\% do crédito imobiliário" no país (CARDOSO; JAENISCH, 2017, p.12).

Diante a este cenário, torna-se cada vez mais indispensáveis a busca de adequação de projetos sustentáveis e processos construtivos que se objetivam em alcançar selos de avaliações ambientais como o Selo Casa Azul da CEF, pois, além da contribuição para a preservação do meio ambiente, as certificações oferecem vantagens competitivas e mercadológicas tanto para as empresas quanto para os seus usuários. Blake (2007) assegura que algumas dessas vantagens são a redução no consumo de água, energia, como também a melhoria da qualidade de vida nas unidades e complexos habitacionais.

Outra vantagem e para incentivo da certificação da Caixa Econômica Federal, como principal agente financiador, oferece ações como a redução das taxas dos financiamentos de apoio à produção nos recursos do Sistema Brasileiro de Poupança e Empréstimo (SBPE) residencial de 9,92\% para 8,80\%, redução do financiamento de apoio à produção das Micro e Pequenas Empresas (MPE/Residencial) de 11,50\% para 9,30\%, redução do Plano Empresa da Construção Civil (PEC) residencial SBPE de 10,30\% para 8,80\%, estão sendo ofertadas para o financiamento dos empreendimentos voluntariados a 
graduação da certificação no nível Prata ou Ouro, além do valor máximo de $\mathrm{R} \$ 328,00$ para os custos do acompanhamento avaliativo da Caixa Econômica Federal (BENEVIDES, 2012).

\section{METODOLOGIA}

Esta pesquisa tem origem exploratória e aplicada, partindo de uma revisão de literatura e análise documental para coleta de dados e estabelecimento dos critérios de análise. Para o seu desenvolvimento, foram consideradas as etapas de: formulação do problema, definição dos proponentes investigados, coleta dos dados, avaliação e análise dos dados.

$\mathrm{Na}$ formulação do problema abordou-se revisão de literatura sobre certificações ambientais e a análise documental do Selo Casa Azul da Caixa Econômica Federal (CEF) de modo direto com download no site da CEF.

$\mathrm{Na}$ coleta das informações necessárias, listaram-se dezoito empreendimentos (casos) dos 26 que receberam certificações em diversos níveis, por cumprirem dezenove critérios obrigatórios em comum.

Com a obtenção e cruzamentos dos critérios de livre escolha atendidos pelos empreendimentos certificados pela CEF, foram geradas tabelas com os critérios de livre escolha atendidos por estes, procedendo-se nos resultados e discursões deste artigo.

\section{RESULTADOS E DISCUSSÕES}

A partir das análises dos trinta e quatro critérios de livre escolha que poderiam ser cumpridos pelos vinte e seis proponentes certificados com o Selo Casa Azul da Caixa Econômica Federal (CEF), foram identificados e caracterizados os critérios de livre escolha de dezoito empreendimentos, sendo considerados como, que "não foi possível ser verificado" os critérios atendidos, nos demais empreendimentos que no caso são estes; Vila dos Atletas 1, 2, 3, 4, 5, 7 e 9 e o Residencial Diamante do Lago, onde não foram encontradas suas fichas de atendimento no site da Caixa Econômica Federal.

Na análise e cruzamento dos dados encontrados percebeu-se que na Categoria 01 (qualidade urbana), que em nenhum dos casos o critério de "Reabilitação de Imóveis" foi atendido, pois, todos os imóveis em questão partiram de novas construções (Quadro 01). Diante isto, apresenta-se como potencial diferencial desta categoria para novos proponentes esta última categoria. Já o critério de "Melhorias do Entorno", se apresentam como o item desta categoria onde melhor percebe-se 0 atendimento onde treze dos dezoito empreendimentos atenderam a esta.

O critério de "Recuperação de Àreas Degradadas", apenas três entre os dezoito empreendimentos atenderam a este critério, levando a reflexão que esta não é uma prática que vem sendo implantada com frequência em projetos de edifícios multifamiliares residenciais que buscam a certificação. A partir disto, os resultados de critérios com pouco atendimento, serão considerados como um critério de baixa implantação em projetos de habitações multifamiliares que buscam a certificação da CEF. Como também, os que alcançaram os maiores números de atendimentos, serão considerados "critérios com alto índice de implantação em projetos certificados pela CEF. 
Quadro 01 - Atendimento aos critérios de livre escolha entre os empreendimentos certificados pela CEF na Categoria 01

\begin{tabular}{|c|c|c|c|c|c|c|c|c|c|c|c|c|c|c|c|c|c|c|c|c|}
\hline \multirow[b]{3}{*}{$\begin{array}{c}\text { Critérios da Categoria } 01 \text { - } \\
\text { Qualidade Urbana }\end{array}$} & \multicolumn{20}{|c|}{$\begin{array}{l}\text { Edifícios Certificados Com o Selo Casa Azul da Caixa Econômica Federal e Ano de } \\
\text { obtenção do Selo }\end{array}$} \\
\hline & $\overline{\bar{s}}$ & $\frac{\text { กั }}{\text { พ }}$ & กั้ & กับ & พิ & ণั่ & ণั) & กับ & $\frac{2}{2}$ & ๙ัก & กั & $\frac{2}{2}$ & ฮั & ๙ั) & กั & กิ & $\hat{\bar{\alpha}}$ & $\overline{\mathrm{\delta}}$ & $\overline{\mathrm{s}}$ & กั \\
\hline & $\begin{array}{l}\overline{\bar{d}} \\
\overline{0} \\
0 \\
\dot{0} \\
\dot{0} \\
\propto\end{array}$ & 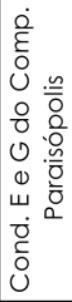 & 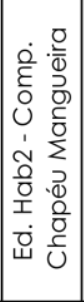 & 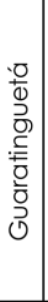 & 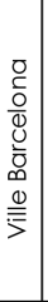 & 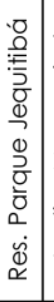 & 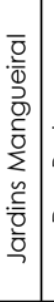 & 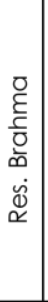 & 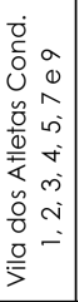 & 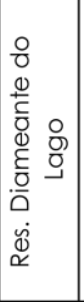 & $\begin{array}{l}0 \\
\frac{0}{0} \\
0 \\
0 \\
0 \\
0 \\
0 \\
0 \\
0 \\
. \overline{0} \\
0 \\
\dot{0} \\
\alpha\end{array}$ & 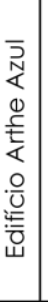 & 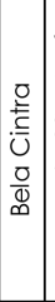 & 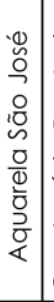 & 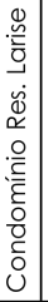 & 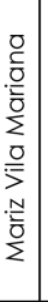 & 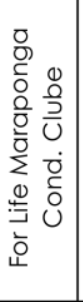 & 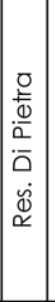 & 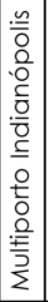 & 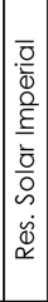 \\
\hline \multicolumn{21}{|l|}{ Melhorias no Entorno } \\
\hline \multicolumn{21}{|l|}{$\begin{array}{l}\text { Recuperação de Áreas } \\
\text { Degradadas }\end{array}$} \\
\hline \multicolumn{21}{|l|}{ Reabilitação de Imóveis } \\
\hline \multicolumn{21}{|c|}{ Legenda } \\
\hline Atendeu ao critéric & & & Não fc & oi po & ossív & el ve & erific & & & O crit & téri & ก & & Di & & & & Ião a & en & ideu \\
\hline
\end{tabular}

Fonte: Autores (2019)

Ao averiguar os critérios da Categoria 02 (projeto e conforto), verifica-se uma média de cumprimento de $50 \%$ em cinco dos seis critérios de livre escolha desta categoria, percebido no Quadro 02, desta forma, esta categoria tem alto índice de implantação em projetos certificados pela CEF. Já o critério de "Ventilação e lluminação natural de banheiros" percebe-se que somente sete proponentes dos dezoito atenderam este critério em seus projetos, podendo ser considerada o critério com menores índices de implantação em projetos certificados pela CEF.

\section{Quadro 02 - Atendimento aos critérios de livre escolha entre os empreendimentos certificados pela CEF na Categoria 02}

\begin{tabular}{|c|c|c|c|c|c|c|c|c|c|c|c|c|c|c|c|c|c|c|c|c|}
\hline \multirow[b]{3}{*}{$\begin{array}{c}\text { Critérios de livre escolha } \\
\text { da Categoria } 02 \text { - Projeto e } \\
\text { Conforto }\end{array}$} & \multicolumn{20}{|c|}{$\begin{array}{l}\text { Edifícios Certificados Com o Selo Casa Azul da Caixa Econômica Federal e Ano de } \\
\text { obtenção do Selo }\end{array}$} \\
\hline & $\overline{\bar{c}}$ & $\stackrel{\text { ก }}{\text { พ }}$ & $\underset{\mathfrak{c}}{\mathbf{n}}$ & $\check{4}^{4}$ & $\overline{2}^{4}$ & $\check{2}^{4}$ & $\overline{2}^{2}$ & $\overline{2}^{2}$ & $\tilde{\Omega}^{2}$ & 造 & $\frac{\text { s. }}{2}$ & $\frac{\text { กั }}{2}$ & $\check{\Upsilon}^{2}$ & $\check{\Upsilon}^{2}$ & $\check{\Upsilon}^{2}$ & $\overline{\mathrm{s}}$ & $\widehat{\bar{\alpha}}$ & $\overline{2}$ & $\overline{\text { กิ }}$ & กิ \\
\hline & $\begin{array}{l}\overline{\bar{\alpha}} \\
\overline{0} \\
0 \\
0 \\
\dot{0} \\
\dot{\alpha} \\
\end{array}$ & 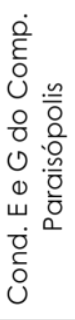 & 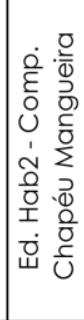 & 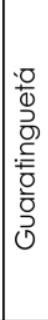 & 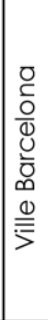 & 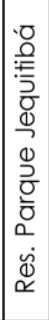 & 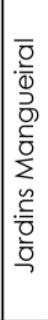 & 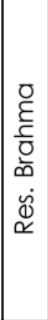 & 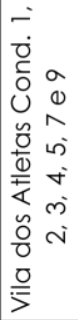 & 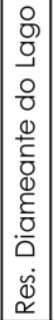 & $\begin{array}{l}0 \\
\overline{0} \\
0 \\
0 \\
0 \\
0 \\
0 \\
0 \\
0 \\
\dot{0} \\
0 \\
\dot{0} \\
\dot{0} \\
\alpha\end{array}$ & 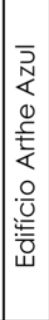 & 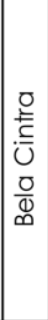 & $\begin{array}{l}0 \\
0 \\
0 \\
0 \\
0 \\
0 \\
0 \\
0 \\
0 \\
00 \\
00 \\
0 \\
0 \\
0 \\
\\
\end{array}$ & 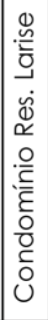 & 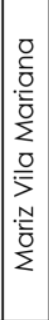 & 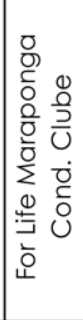 & 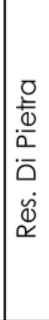 & 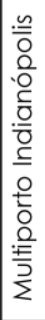 & 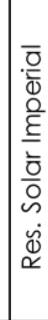 \\
\hline \multicolumn{21}{|l|}{ Flexibilidade de Projeto } \\
\hline \multicolumn{21}{|l|}{ Relação com a Vizinhança } \\
\hline \multicolumn{21}{|l|}{$\begin{array}{l}\text { Solução Alternativa de } \\
\text { transporte }\end{array}$} \\
\hline \multicolumn{21}{|l|}{$\begin{array}{l}\text { Iluminação Natural de } \\
\text { Áreas Comuns }\end{array}$} \\
\hline \multicolumn{21}{|l|}{$\begin{array}{l}\text { Ventilação e lluminação } \\
\text { Natural de Banheiros }\end{array}$} \\
\hline \multicolumn{21}{|l|}{$\begin{array}{l}\text { Adequação às Condições } \\
\text { Físicas do Terreno }\end{array}$} \\
\hline \multicolumn{21}{|c|}{ Legenda } \\
\hline
\end{tabular}


Na Categoria 3 (eficiência energética), pode-se observar, nos critérios de "Sistema de Aquecimento Solar" e "Sistemas de Aquecimento a Gás", que apenas três entre os dezoito proponentes identificados atenderam a este critério. O critério de "Fontes Alternativas de Energia", encontra-se com apenas dois empreendimentos que atenderam a este critério diferencial aos proponentes, pois, obteve apenas dois empreendimentos que atenderam a este critério, demonstrando o critério menos usual em implantações nos projetos empreendimentos certificados pela CEF. O critério de "Elevadores Eficientes", percebe-se ser o critério mais usual em empreendimentos certificados pela CEF como mostra o Quadro 3.

\section{Quadro 03 - Atendimento aos critérios de livre escolha entre os empreendimentos certificados pela CEF na Categoria 03}

\begin{tabular}{|c|c|c|c|c|c|c|c|c|c|c|c|c|c|c|c|c|c|c|c|c|}
\hline \multirow[b]{3}{*}{$\begin{array}{l}\text { Critérios de livre escolha } \\
\text { da Categoria } 03 \text { - } \\
\text { Eficiência Energética }\end{array}$} & \multicolumn{20}{|c|}{$\begin{array}{l}\text { Edifícios Certificados Com o Selo Casa Azul da Caixa Econômica Federal e Ano de } \\
\text { obtenção do Selo }\end{array}$} \\
\hline & $\overline{\bar{\Sigma}}$ & $\frac{\text { กิ }}{\mathfrak{4}}$ & $\frac{\text { กิ }}{\mathfrak{n}}$ & กับ & $\frac{\text { บิ }}{2}$ & $\frac{2}{2}$ & בับ & พั) & 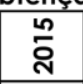 & กั & 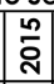 & $\frac{\text { ก }}{2}$ & ลั่ & กั & กั & กิ & กิ & กิ & กั & กิ \\
\hline & 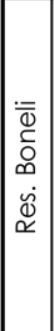 & 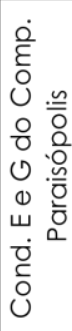 & 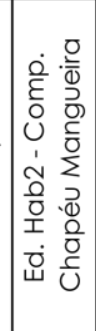 & 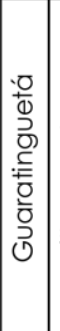 & 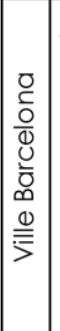 & 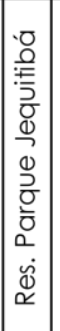 & 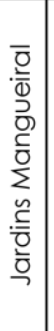 & 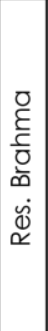 & 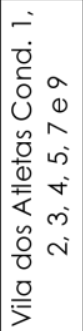 & 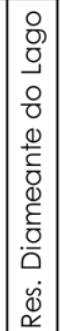 & 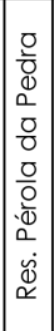 & 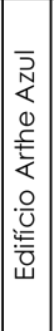 & 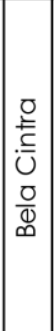 & \begin{tabular}{|l|}
0 \\
0 \\
0 \\
0 \\
0 \\
0 \\
0 \\
0 \\
0 \\
0 \\
0 \\
0 \\
0 \\
\\
\end{tabular} & 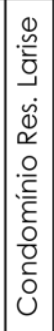 & 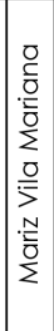 & 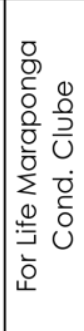 & 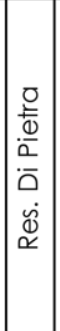 & 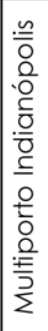 & 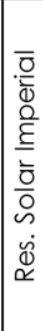 \\
\hline \multicolumn{21}{|l|}{$\begin{array}{l}\text { Sistema de Aquecimento } \\
\text { Solar }\end{array}$} \\
\hline \multicolumn{21}{|l|}{$\begin{array}{l}\text { Sistemas de Aquecimento } \\
\text { à Gás }\end{array}$} \\
\hline \multicolumn{21}{|l|}{ Elevadores Eficientes } \\
\hline \multicolumn{21}{|l|}{ Eletrodomésticos Eficientes } \\
\hline \multicolumn{21}{|l|}{\begin{tabular}{|l|} 
Fontes Alternativas de \\
Energia
\end{tabular}} \\
\hline \multicolumn{21}{|c|}{ Legenda } \\
\hline Atendeu ao critério & & & Não foi & possí & sível & verit & ficar & & & O cri & itéri & onã & iose & apli & & & & ão at & tenc & \\
\hline
\end{tabular}

Para a Categoria 04 (conservação de recursos materiais) percebe-se como principal critério no qual merece destaque, o de "Pavimentação com RCD", nenhum empreendimento dentre os dezoito analisados, utilizou esta tecnologia em seus projetos. Com isto identifica-se como um critério que não atende as tecnologias implantadas em empreendimentos certificados pela CEF e que indagações são alavancadas diante isto como uma hipótese de não domínio de tal tecnologia pelos empreendimentos, ou da não viabilidade de implantação deste critério. Observa-se também, que o critério com maior índice de atendimento é o de "Facilidade de Manutenção da Fachada", onde quatorze entre os dezoito empreendimentos atenderam a este, sendo considerado o critério de maior domínio em tecnologia para implantação em empreendimentos certificados pela CEF.

Outro critério que neste mesmo sentido identifica-se bastante usual em sua aplicação, é o da utilização da madeira no critério de "Madeira Plantada ou Certificada", em que treze entre os dezoito empreendimentos certificados aplicaram esta tecnologia em seus projetos. Assim considera-se também, 
como um critério bastante comum entre os empreendimentos certificados pela CEF (Quadro 04).

Quadro 04 - Atendimento aos critérios de livre escolha entre os empreendimentos certificados pela CEF na Categoria 04

\begin{tabular}{|c|c|c|c|c|c|c|c|c|c|c|c|c|c|c|c|c|c|c|c|c|}
\hline \multirow{3}{*}{$\begin{array}{l}\text { Critérios de livre escolha } \\
\text { da Categoria } 04 \text { - } \\
\text { Conservação de Recursos } \\
\text { Materiais }\end{array}$} & \multicolumn{20}{|c|}{$\begin{array}{l}\begin{array}{l}\text { Edifícios Certificados Com o Selo Casa Azul da Caixa Econômica Federal e Ano de } \\
\text { obtenção do Selo }\end{array} \\
\end{array}$} \\
\hline & $\overline{\bar{\alpha}}$ & กั่ & 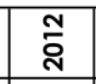 & ลั่ & 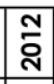 & \begin{tabular}{|c|}
$\mathfrak{n}$ \\
\end{tabular} & 帘 & กั & $\overbrace{}^{\frac{2}{2}}$ & กับ & กั & $\frac{2}{2}$ & ¿ั) & "ั. & ¿ั. & $\overline{\mathrm{s}}$ & $\overline{\frac{4}{2}}$ & 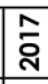 & ลั่ & กิ \\
\hline & $\begin{array}{l} \\
\overline{\bar{d}} \\
\overline{0} \\
\infty \\
\dot{\phi} \\
\widetilde{\Sigma}\end{array}$ & 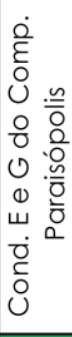 & 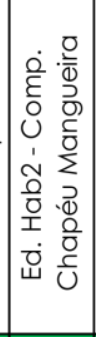 & 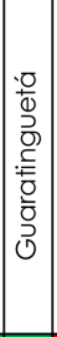 & 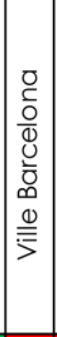 & \begin{tabular}{|c|}
0 \\
0 \\
0 \\
$:$ \\
0 \\
0 \\
0 \\
0 \\
0 \\
0 \\
0 \\
0 \\
0 \\
$\dot{0}$ \\
$\alpha$ \\
$\alpha$ \\
\end{tabular} & 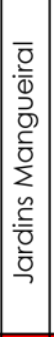 & 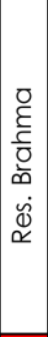 & 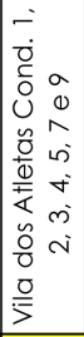 & $\begin{array}{l}0 \\
0 \\
0 \\
0 \\
0 \\
0 \\
0 \\
\frac{0}{c} \\
0 \\
0 \\
\frac{\varepsilon}{0} \\
.0 \\
0 \\
\dot{0} \\
\alpha \\
\alpha\end{array}$ & \begin{tabular}{|l|}
0 \\
$\frac{0}{0}$ \\
0 \\
0 \\
0 \\
0 \\
0 \\
0 \\
0 \\
$\cdot \frac{0}{0}$ \\
$\dot{0}$ \\
$\dot{0}$ \\
$\propto$ \\
\end{tabular} & 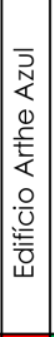 & 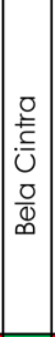 & 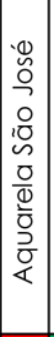 & 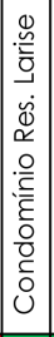 & 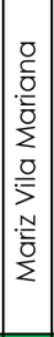 & 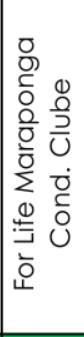 & 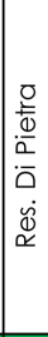 & 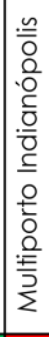 & 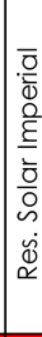 \\
\hline \multicolumn{21}{|l|}{ Modulação de Projeto } \\
\hline \multicolumn{21}{|l|}{$\begin{array}{l}\text { Componentes } \\
\text { Industrializados ou Pré- } \\
\text { fabricados }\end{array}$} \\
\hline \multicolumn{21}{|l|}{$\begin{array}{l}\text { Concreto com Dosagem } \\
\text { Otimizada }\end{array}$} \\
\hline \multicolumn{21}{|l|}{$\begin{array}{l}\text { Cimento de Alto Forno } \\
\text { (CPIII) e Pozolânico (CP IV) }\end{array}$} \\
\hline \multicolumn{21}{|l|}{ Pavimentação com RCD } \\
\hline \multicolumn{21}{|l|}{$\begin{array}{l}\text { Facilidade de Manutenção } \\
\text { da Fachada }\end{array}$} \\
\hline \multirow{2}{*}{\multicolumn{21}{|c|}{\begin{tabular}{|l|} 
Madeira Plantada ou \\
Certificada
\end{tabular}}} \\
\hline \multicolumn{10}{|c|}{ Legenda } & & & & & & & & & & & \\
\hline Atendeu ao critério & & & Não foi & poss & sível & I ver & ifica & & & O cri & ritéri & onã & ăo se & apli & & & & ão a & ten & \\
\hline
\end{tabular}

Na Categoria 05 (gestão da água), observa-se, que o critério de "Infiltração de Águas Pluviais", encontra-se como o critério menos procurado pelos proponentes ao seu cumprimento, sendo este o diferencial desta categoria para um novo proponente, onde nenhum dos dezoito proponentes atendeu a este critério. Já o critério de "Dispositivos Economizadores - Arejadores" enquadra-se no critério mais viável a ser alcançado pelos proponentes onde apenas três dos dezoito proponentes não incluíram este critério em seus projetos, Quadro 05.

Entre critérios de livre escolha da Categoria 06 (práticas sociais), mostrado no Quadro 06, no critério de "Participação da Comunidade na Elaboração do Projeto" apenas o Condomínio E e G do Complexo Paraisópolis atendeu a este critério. No critério de "Ações para a Geração de Emprego e Renda", além deste último citado e o empreendimento "Jardins Mangueiral" foram os únicos a atenderem entre os dezoito empreendimentos, portanto, encontram-se nesta categoria como os critérios com menores aplicações em projetos de edificações certificadas pela CEF. Já os critérios de "Desenvolvimento Pessoal dos Empregados", "Inclusão de trabalhadores locais" e "Educação Ambiental dos Moradores", aparecem como os mais viáveis em serem alcançados pelos proponentes, sendo estes considerados como os critérios de livre escolha com mais viabilidade no atendimento entre os empreendimentos certificados pela Caixa Econômica Federal. 
Quadro 05 - Atendimento aos critérios de livre escolha entre os empreendimentos certificados pela CEF na Categoria 05

\begin{tabular}{|c|c|c|c|c|c|c|c|c|c|c|c|c|c|c|c|c|c|c|c|c|}
\hline \multirow[b]{3}{*}{$\begin{array}{c}\text { Critérios de livre escolha } \\
\text { da Categoria } 05 \text { - Gestão } \\
\text { da água }\end{array}$} & \multicolumn{20}{|c|}{$\begin{array}{c}\text { Edifícios Certificados Com o Selo Casa Azul da Caixa Econômica Federal e Ano de } \\
\text { obtenção do Selo }\end{array}$} \\
\hline & $\overline{\bar{s}}$ & $\overline{\check{C}}^{\mathrm{N}}$ & $\frac{\mathfrak{c}^{2}}{\mathrm{~N}}$ & 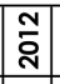 & ธั่ & 帘 & กั่ & $\overline{\mathscr{C}}^{\mathrm{N}}$ & 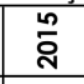 & กั & กั & กั & $\overline{\mathrm{N}}^{\mathrm{N}}$ & ๙ั) & సั. & $\overline{\bar{c}}$ & กั่ & ฉิ & $\overline{\check{c}}$ & $\overline{\check{c}}$ \\
\hline & $\begin{array}{l}\overline{\bar{d}} \\
\overline{0} \\
\bar{\infty} \\
\dot{\omega} \\
\alpha \\
\dot{0}\end{array}$ & 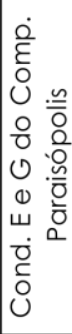 & 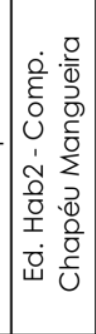 & \begin{tabular}{|c|}
0 \\
0 \\
0 \\
0 \\
0 \\
.$\frac{5}{0}$ \\
0 \\
0 \\
0 \\
0 \\
0
\end{tabular} & 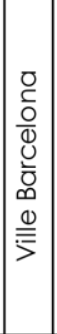 & 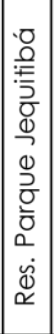 & 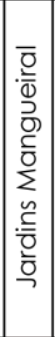 & 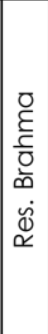 & 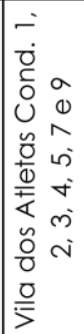 & 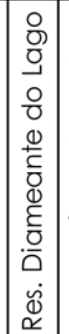 & 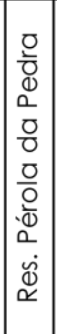 & 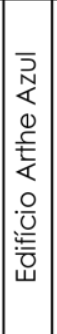 & 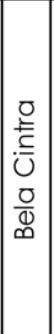 & 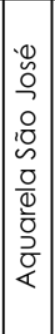 & 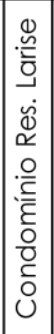 & 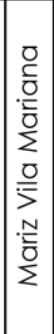 & 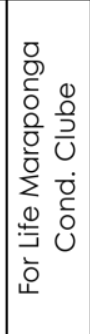 & 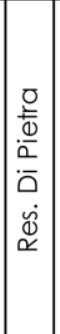 & 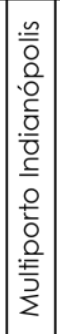 & 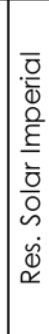 \\
\hline \multicolumn{21}{|l|}{$\begin{array}{l}\text { Dispositivos } \\
\text { Economizadores - } \\
\text { Arejadores }\end{array}$} \\
\hline \multicolumn{21}{|l|}{$\begin{array}{l}\text { Dispositivos } \\
\text { Economizadores - Outros } \\
\text { Reguladores de vazão }\end{array}$} \\
\hline \multicolumn{21}{|l|}{$\begin{array}{l}\text { Aproveitamento de Águas } \\
\text { Pluviais }\end{array}$} \\
\hline \multicolumn{21}{|l|}{$\begin{array}{l}\text { Retenção de Águas } \\
\text { Pluviais }\end{array}$} \\
\hline \multirow{2}{*}{\multicolumn{21}{|c|}{$\begin{array}{l}\text { Infiltração de Águas } \\
\text { Pluviais }\end{array}$}} \\
\hline & & & & & & & & & & & & & & & & & & & & \\
\hline Atendeu ao critério & & & Não foi & poss & sível & Iver & rifica & & & O cri & itéric & o nã & áo se & apli & & & & ão at & atend & deu \\
\hline
\end{tabular}

Nota-se também, que a certificação da CEF, permite o acréscimo de critérios aos já pré-estabelecidos pela certificadora, identifica-se que 0 empreendimento "For Life Maraponga Condomínio Clube - Residencial Liberdade", somou ao quantitativo de critérios atendidos, um "Critério Bônus", ao apresentar em seus projetos o critério de "Obra Viva" e "Lar Verde Lar", sendo aprovado pelo Selo e assim, atendendo ao quantitativo da certificação nível "Ouro", devido ao cumprimento dos 19 critérios obrigatórios e mais 12 critérios de livre (com o cumprimento do critério bônus) somando-se os 31 critérios atendidos correspondente a esse nível.

Diante do exposto, observa-se os critérios de livre escolha usualmente mais comuns em práticas projetuais em edifícios certificados pelo Selo Casa Azul da Caixa Econômica Federal. Considerando estes, os mais viáveis a serem postos em prática diante diferenças tecnológicas e de métodos construtivos. Verificase também critérios pouco utilizados em empreendimentos, considerando estes os critérios menos usuais em empreendimentos certificados pela CEF, por tanto, pouco aplicáveis em projetos e na prática construtiva, em empreendimentos característicos do selo. Os menos atendidos são considerados como diferenciais a serem cumpridos por novos proponentes, promovendo o aumento na competitividade, melhoria tecnológica e busca por soluções inovadoras para edificações mais sustentáveis. 


\section{Quadro 06 - Atendimento aos critérios de livre escolha entre os empreendimentos} certificados pela CEF na Categoria 06

\begin{tabular}{|c|c|c|c|c|c|c|c|c|c|c|c|c|c|c|c|c|c|c|c|c|}
\hline \multirow[b]{3}{*}{$\begin{array}{c}\text { Critérios de livre escolha } \\
\text { da Categoria } 06 \text { - Práticas } \\
\text { Sociais }\end{array}$} & \multicolumn{20}{|c|}{$\begin{array}{l}\text { Edifícios Certificados Com o Selo Casa Azul da Caixa Econômica Federal e Ano de } \\
\text { obtenção do Selo }\end{array}$} \\
\hline & $\overline{\mathrm{s}}$ & $\bar{\Upsilon}^{\text {ก }}$ & $\bar{\Upsilon}^{\frac{4}{2}}$ & 帘 & $\bar{\Upsilon}^{\mathrm{N}}$ & พั) & กับ & $\bar{\Upsilon}^{\mathrm{N}}$ & $\frac{\text { ก }}{2}$ & กั่ & กั & กั & ¿ั) & ๙ั) & กั & กั & กับ & ธิ่ & กิ & $\overline{\delta^{2}}$ \\
\hline & $\begin{array}{l}: \overline{\bar{\omega}} \\
\overline{0} \\
\propto \\
\dot{\tilde{\omega}} \\
\propto\end{array}$ & 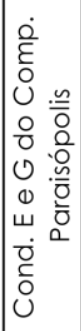 & 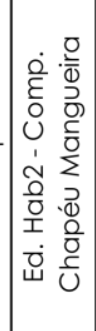 & 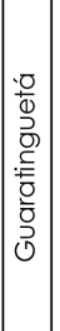 & 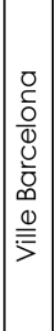 & 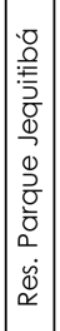 & 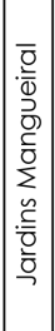 & 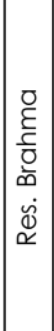 & 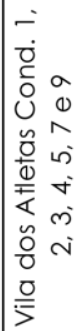 & 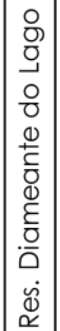 & 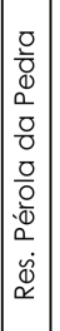 & 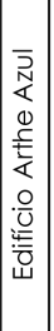 & 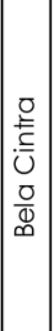 & 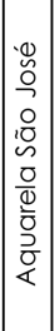 & 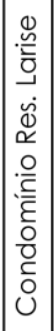 & 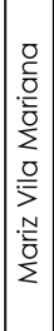 & 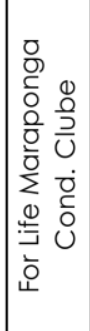 & 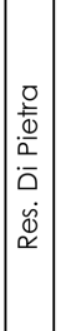 & 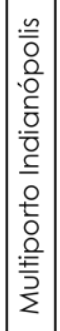 & $\begin{array}{l}\overline{\bar{\sigma}} \\
\overline{\bar{D}} \\
\stackrel{0}{\varrho} \\
\underline{\varepsilon} \\
\bar{z} \\
\overline{0} \\
\tilde{O} \\
\dot{\omega} \\
\alpha\end{array}$ \\
\hline \multicolumn{21}{|l|}{$\begin{array}{l}\text { Desenvolvimento Pessoal } \\
\text { dos Empregados }\end{array}$} \\
\hline \multicolumn{21}{|l|}{$\begin{array}{l}\text { Capacitação Profissional } \\
\text { dos Empregados }\end{array}$} \\
\hline \multicolumn{21}{|l|}{$\begin{array}{l}\text { Inclusão de Trabalhadores } \\
\text { Locais }\end{array}$} \\
\hline \multicolumn{21}{|l|}{$\begin{array}{l}\text { Participação da } \\
\text { Comunidade na } \\
\text { Elaboração do Projeto }\end{array}$} \\
\hline \multicolumn{21}{|l|}{$\begin{array}{l}\text { Educação Ambiental dos } \\
\text { Moradores }\end{array}$} \\
\hline \multicolumn{21}{|l|}{$\begin{array}{l}\text { Capacitação para Gestão } \\
\text { do Empreendimento }\end{array}$} \\
\hline \multicolumn{21}{|l|}{$\begin{array}{l}\text { Ações para Mitigação de } \\
\text { Riscos Sociais }\end{array}$} \\
\hline \multicolumn{21}{|l|}{$\begin{array}{l}\text { Ações para a Geração de } \\
\text { Emprego e Renda }\end{array}$} \\
\hline \multicolumn{21}{|l|}{$\begin{array}{l}\text { Critério Bônus: "Obra Viva" } \\
\text { e "Lar Verde Lar" }\end{array}$} \\
\hline \multicolumn{21}{|c|}{ Legenda } \\
\hline Atendeu ao critério & & & Não foi & poss & sível & I veri & rifica & & & O cri & itéric & onã & áo se & e apl & & & & ão at & tend & \\
\hline
\end{tabular}

No Quadro 07, observa-se quais os critérios livres de cada categoria que mais foram atendidos pelos proponentes, diante um percentual de atendimento entre os dezoito empreendimentos. Com maiores índices de atendimento está o critério de "dispositivos economizadores arejadores" em que 83,33\% dos empreendimentos implantaram esta tecnologia. $\bigcirc$ critério de "facilidade de manutenção da fachada" foi atendido por $77,77 \%$ dos empreendimentos. Entre outros percebidos no Quadro 07, que somam 16 no total de critérios que foram atendidos por mais da metade dos empreendimentos certificados.

Na Quadro 08, estão descritos os dados dos critérios com menores índices de atendimentos pelos empreendimentos, fazendo destes critérios, potenciais diferenciais de implantação em empreendimentos com fins competitivos que visam a importância do empreendimento no mercado de edificações com desenvolvimento sustentável. 
Quadro 07 - Critérios de livre escolha mais comuns em práticas projetuais nos empreendimentos certificados pela CEF

\begin{tabular}{|c|c|c|}
\hline Categorias & Critérios & Percentuais \\
\hline $\begin{array}{c}\text { Categoria 01: Qualidade } \\
\text { Urbana }\end{array}$ & - Melhorias no entorno & $72,20 \%$ \\
\hline \multirow{5}{*}{$\begin{array}{l}\text { Categoria 02: Projeto e } \\
\text { conforto }\end{array}$} & - Flexibilidade de Projeto & $55,55 \%$ \\
\hline & -Solução alternativa de transporte & $55,55 \%$ \\
\hline & $\begin{array}{l}\text { • Adequação às condições físicas } \\
\text { do terreno }\end{array}$ & $55,55 \%$ \\
\hline & • Relação com a vizinhança & $50 \%$ \\
\hline & $\begin{array}{l}\text {-lluminação natural de áreas } \\
\text { comuns }\end{array}$ & $50 \%$ \\
\hline \multirow{2}{*}{$\begin{array}{c}\text { Categoria 03: Eficiência } \\
\text { Energética }\end{array}$} & - Elevadores eficientes & $61,11 \%$ \\
\hline & -Eletrodomésticos eficientes & $50 \%$ \\
\hline \multirow{3}{*}{$\begin{array}{l}\text { Categoria 04: Conservação de } \\
\text { recursos materiais }\end{array}$} & $\begin{array}{l}\text { - Concreto com dosagem } \\
\text { otimizada }\end{array}$ & $50 \%$ \\
\hline & $\begin{array}{l}\text { - Facilidade de manutenção da } \\
\text { fachada }\end{array}$ & $77,77 \%$ \\
\hline & - Madeira plantada ou certificada & $72,22 \%$ \\
\hline Categoria 05: Gestão da água & $\begin{array}{l}\text {-Dispositivos economizadores - } \\
\text { arejadores }\end{array}$ & $83,33 \%$ \\
\hline \multirow{4}{*}{ Categoria 06: Práticas Sociais } & $\begin{array}{l}\text { - Desenvolvimento pessoal dos } \\
\text { empregados }\end{array}$ & $66,66 \%$ \\
\hline & $\begin{array}{l}\text { - Capacitação profissional dos } \\
\text { empregados }\end{array}$ & $50 \%$ \\
\hline & - Inclusão de trabalhadores locais & $66,66 \%$ \\
\hline & $\begin{array}{l}\text { - Educação ambiental dos } \\
\text { moradores }\end{array}$ & $66,66 \%$ \\
\hline \multicolumn{2}{|c|}{ Total de critérios com índices superiores a $50 \%$ atendidos } & 16 \\
\hline
\end{tabular}

Quadro 08 - Critérios de livre escolha das seis categorias com os menores índices de atendimento entre as seis categorias

\begin{tabular}{|c|c|c|}
\hline Categorias & Critérios & Percentuais \\
\hline Categoria 01: Qualidade Urbana & - Reabilitação de Imóveis & $0 \%$ \\
\hline Categoria 02: Projeto e conforto & $\begin{array}{c}\text { - Ventilação e iluminação } \\
\text { natural de banheiros }\end{array}$ & $38,88 \%$ \\
\hline $\begin{array}{l}\text { Categoria 03: Eficiência } \\
\text { Energética }\end{array}$ & - Fontes alternativas de energia & $11,11 \%$ \\
\hline $\begin{array}{l}\text { Categoria 04: Conservação de } \\
\text { recursos materiais }\end{array}$ & -Pavimentação com RCD & $0 \%$ \\
\hline Categoria 05: Gestão da água & - Infiltração de águas pluviais & $0 \%$ \\
\hline Categoria 06: Práticas Sociais & $\begin{array}{c}\text { - Participação da comunidade } \\
\text { na elaboração do projeto } \\
\text { • Ações para a geração de } \\
\text { emprego e renda }\end{array}$ & $\begin{array}{l}5,55 \% \\
11,11 \%\end{array}$ \\
\hline Total de critérios com men & es índices de atendimento & 7 \\
\hline
\end{tabular}

Fonte: Autores (2019)

\section{CONSIDERAÇÕES FINAIS}

O Selo Casa Azul da Caixa Econômica Federal, criado para certificação ambiental nacional de habitação, é um selo com alto potencial para certificação ambiental. Porém, a divulgação e o interesse por esta 
certificação parece ser um dos maiores desafios para a disseminação da adesão. Desta forma, os resultados mostrados nos Quadros 07 e 08 dispõe de dados estratégicos para o atendimento de critérios, visando a obtenção do Selo Ouro.

Através dos dados encontrados no Quadro 07, onde são expostos os critérios mais usuais em projetos certificados, ao somar os critérios obrigatórios (19) com os critérios mais aplicáveis encontrados neste trabalho (16), resultam-se em 35 critérios atendidos, referenciando-se a graduação Ouro do selo Casa Azul. Estes resultados podem ser vistos como uma ferramenta de simulação de certificação, que pode ser usado por futuros proponentes para o atendimento de mais critérios e atingir pontuações mais altas.

Com os resultados presentes no Quadro 08, propõe-se difundir os critérios não atendidos até o presente, para que propostas futuras diferenciadas e inovadoras sejam implantadas nos empreendimentos, promovendo índices de sustentabilidade no selo mais competitivas. Isso abre portas para implantação de novas soluções e tecnologias sustentáveis, que por sua vez, trazem contribuições para o usuário e para o empreendedor.

\section{AGRADECIMENTOS}

Ao Grupo de Pesquisa INOVA, ao Programa de Pós-Graduação em Arquitetura e Urbanismo da UFV, e à CAPES pela bolsa de estudos.

\section{REFERÊNCIAS}

CAIXA ECONÔMICA FEDERAL. Guia Caixa: sustentabilidade ambiental. 2010. Disponível em:

<http://www.caixa.gov.br/Downloads/selo_casa_azul/Selo_Casa_Azul.pdf>. Acesso em: 10 mar. 2019.

CAMPOS, M. A.; FERRÃO, A. M. D. A. Engenharia de empreendimentos sustentáveis: classes de uso e níveis de certificação dos empreendimentos certificados no estado de São Paulo. Revista Eletrônica de Engenharia Civil, Goiás, v. 14, n. 1, p. 191-203, janeiro - junho 2018. ISSN 1. Disponível em: <https://www.revistas.ufg.br/reec/article/view/44803>. Acesso em: 29 abr. 2019.

DINAMARCO, C. P. G. Selo Casa Azul certificação ambiental: estudo de caso. Dissertação (Mestrado em Engenharia Ambiental) - Escola Politécnica, Universidade Federal do Rio de Janeiro, Rio de Janeiro, 2016.

GRÜNBERG, P. R. M.; MEDEIROS, M. H. F.; TAVARES, S. F. Certificação ambiental de habitações: comparação entre LEED for homes, processo AQUA e selo casa azul. Ambiente \& Sociedade, Campinas, v. 17, n. 2, p. 195-214, 2 abriljunho. 2014.

ROCHA, C. R.; FALCÃO, D. F. Comparação entre as principais certificações ambientais: AQUA, LEED e Selo Casa AzUl. 17 Conferência Internacional da LARES, São Paulo, 13 a 15 de setembro de 2017. 1-19.

SILVA, V. G. Avaliação da sustentabilidade de edifícios de escritórios

brasileiros: diretrizes e base metodológica. 2003. 210 f. Tese (Doutorado em Engenharia) - Departamento de Engenharia de Construção Civil, Escola Politécnica, Universidade de São Paulo, 2003. 
TOMÁS, E. M. M.; LINS, D. P. Informações para pesquisa sobre o Selo Casa Azul da Caixa. [Mensagem pessoal]. Mensagem recebida por: <gehpa02@caixa.gov.br>em: 25 de abril de 2019.

ZANDEMONIGNE, R. T.; TIBÚRCIO, T. M. S. A sustentabilidade em seis dimensões: recomendações para a habitação sustentável a partir de critérios do Selo Casa Azul. In: CASTAÑON, J. A. B.; HIPPERT, M. A. S.; BARBOSA, M. T. G. (Org.). Ambiente Construído: Projeto, Técnica e Gestão. led. Juiz de Fora: Templo, 2013, v.1, p. 105-110. 